\title{
Non-Metastatic Carcinoma
}

National Cancer Institute

\section{Source}

National Cancer Institute. Non-Metastatic Carcinoma. NCI Thesaurus. Code C9481.

Carcinoma that is confined to the site in which it initially manifested. 